УДК $338.1+331.104$

JEL O14, O15, J24

ЭВОЛЮЦИЯ ТРУДОВЫХ ОТНОШЕНИЙ В РЕСПУБЛИКЕ БЕЛАРУСЬ В КОНТЕКСТЕ ЦИФРОВИЗАЦИИ И РОБОТИЗАЦИИ ЭКОНОМИКИ ${ }^{1}$

В. В. Богатырева

доктор экономических наук, профессор, ректор Витебский государственный университет имени П. М. Машерова г. Витебск, Республика Беларусь

М. Ю. Бобрик bobrikmyu@vsu.by кандидат географических наук, доцент, проректор Витебский государственный университет имени П. М. Машерова г. Витебск, Республика Беларусь

T. В. Сергиевич serhiyevich@bntu.by кандидат экономических наук, доцент, доцент кафедры «Экономика и право» Белорусский национальный технический университет г. Минск, Республика Беларусь

Статья посвящена исследованию эволючии трудовых отношений в Республике Беларусь. В результате выявлено, что динамика трудовых отношений в Республике Беларусь соответствует общемировым тенденциям, обеспечивая переход нашей страны к новому качеству экономического роста. Сделан вывод о том, что положительные эффекты для народного хозяйства будут тем выше, чем в большей степени удастся внедрять ицифровые технологии и роботизированные системы в реальном секторе экономики, а также при наличии действенной государственной системы снижения уровня структурной безработицы, порождаемой дальнейшим развитием иифровой экономики.

Ключевые слова: трудовые отношения, человеческий капитал, мотивация труда, циирровая экономика, роботизация экономики, структурная безработица, рынок труда.

Цитирование: Богатырева, В. В. Эволюция трудовых отношений в Республике Беларусь в контексте цифровизации и роботизации экономики / В. В. Богатырева, М. Ю. Бобрик, Т. В Сергиевич // Экономическая наука сегодня : сб. науч. ст. / БНТУ. Минск, 2021. - Вып. 13. - С. 6-14. DOI: 10.21122/2309-6667-2021-13-6-14

Введение. Динамика трудовых отношений в Республике Беларусь носит системный характер и соответствует существующим сегодня глобальным и региональным тенденциям. Названные тенденции никогда не могут быть равнонаправленными, поскольку, как известно, «целостность процесса развития противоречива, она включает взаимодействия разнонаправленных и противоположных тенденций, одна из которых, как правило, преобладает (в целом же направленность развития правомерно рассматривать как суммарный вектор взаимодействующих тенденций)» [1, с. 9]. Это не

\footnotetext{
${ }^{1}$ Работа выполнена при поддержке БРФФИ (договор с БРФФИ № Г20РА-011 от 04.05.2020 г.).
} 
только обусловливает то, что динамика трудовых отношений в нашей стране в результате цифровизации экономики не может происходить только под влиянием этого фактора, а значит на нее будут еще оказывать воздействие многие другие факторы, в том числе: социальный характер белорусского государства; сложившаяся структура экономики вообще и реального сектора в частности с соответствующей структурой занятости (а значит и соответствующих профессионально-квалификационных навыков и компетенций занятого населения); инертность и известная самостоятельность системы подготовки кадров и требований к кадрам, предъявляемых современным этапом научно-технической революции, а также психологическая неготовность части населения осваивать новые технологии, т. е. сегодня еще больше актуализируется «проблема повышения адаптивности развития человеческого потенциала к потребностям инновационного развития» [2, с. 12], и многое другое. Из этого вытекает то, что динамика трудовых отношений в Республике Беларусь будет включать в себя как количественные, так и качественные изменения; как изменения, которые лежат на поверхности явлений и могут быть описаны при помощи количественных методов, так и латентные изменения, которые не могут быть без очень значительных содержательных искажений описаны математически, и поэтому при их анализе потребуется использовать преимущественно качественные характеристики. Целью данной работы является анализ качественных изменений трудовых отношений в Республике Беларусь в контексте цифровой трансформации и роботизации экономики.

Результаты и их обсуждение. Анализ динамики трудовых отношений в условиях цифровизации экономики усложняется тем, что качественные изменения в характере труда и человеческом капитале под воздействием цифровизации статистически не отражаются. И поскольку «цифровизация охватывает не только производственнотехнологические процессы хозяйственной деятельности, но и всю совокупность общественных отношений, складывающихся по поводу реализации человеком способности к труду» [3, с. 8], количественно отразить данное влияние цифровизации в полной мере в принципе невозможно. Таким образом, на наш взгляд, при анализе динамики трудовых отношений в Республике Беларусь в контексте цифровой трансформации экономики правомерно опираться, прежде всего, на феноменологическое видение исследуемого объекта. В противном случае происходит излишняя формализация и морализация предмета исследования, когда рассмотрение сложнейшего процесса эволюции трудовых отношений под воздействием становления и развития информационной экономики в Беларуси, в ряде случаев сопровождаемое усилением противоречий интересов между традиционными, новыми и новейшими организационнотехнологическими укладами, сводится к упрощенным, излишне оптимистичным и идеализированным обобщениям. Так, например, белорусский экономист Г. Г. Головенчик в статье «Трансформация рынка труда в цифровой экономике» категорически заявляет: «Развитие трудовых отношений в цифровой экономике приводит к замене постоянного штата временными исполнителями, при этом многие виды работ могут выполняться за тысячи километров от офиса и даже за пределами национальных границ. Заметным трендом последних лет стал очень быстрый рост числа внештатных сотрудников-фрилансеров. Так, только в США в 2017 г. насчитывалось 57,3 млн человек, работающих в режиме фриланса (в т. ч. по совместительству), что составляет $36 \%$ работающего населения страны» [4, с. 28]. Далее названный автор, развивая этот тезис, утверждает, что «увеличение независимости работника (в цифровой экономике примечание авторов) формирует между ним и руководителем особый род партнерских отношений, требующих соответствующего роста доверия. Специалист сам формирует портфель заказов, согласовывает объем и сроки выполнения работ, а также размер собственного вознаграждения» $[4$, с. 28]. Таким образом, по мнению Г. Г. Головенчик, получается, что отношения собственности на материальные и финансовые 
факторы производства отходят на задний план, оказывая незначительное влияние на распределение прибавочной стоимости. В этом «информационном коммунизме» исчезает частная собственность на средства производства.

По нашему мнению, названный тезис является скорее мечтой отдельных ученых-философов и экономистов, а никак не реалиями рыночной экономики, основой на частной и смешанной формах собственности, в связи со следующими обстоятельствами. Во-первых, собственник на средства производства (факторы производства) всегда стремится к увеличению своего персонифицированного дохода, как правило в форме прибыли, а значит его готовность передавать большую долю добавленной стоимости наемному работнику ограничивается многими субъектными факторами, в том числе и альтернативными способами получения дохода собственником финансового капитала - например, покупкой им акций более доходных компаний, размещением их на депозитах в банках. Во-вторых, как показывает практика, значительное количество работников цифрового хозяйственного уклада обладают навыками и компетенциями, получение которых требует незначительного времени. Кроме того, как нами уже отмечалось ранее, «обратной стороной увеличивающегося доступа к знаниям является быстрое их обесценивание и полураспад компетентности, что выступает ключевыми ограничителями накопления человеческого капитала в условиях развития цифровой экономики» [5, с. 22]. В-третьих, удаленная занятость, как показывает практика, в ряде случаев оказывает негативное влияние на производительность труда. В-четвертых, опыт дистанционной работы программистов в период коронавирусной пандемии показал, что достаточно часто работнику со стороны нанимателя доводятся такие задания (которые он может выполнять, когда захочет, но если они не будут выполнены в срок, то трудовые отношения с ним будут прерваны), для выполнения которых он тратит намного больше времени, чем если бы он работал 40 часов в неделю в соответствии с Трудовым кодексом Республики Беларусь (при этом в условиях дистанционной работы для контроля пребывания на рабочем месте и работы на компьютере в течение оговоренного в трудовом договоре времени используются специальные компьютерные программы). В-пятых, дифференциация в оплате труда между цифровой элитой и большинством работников цифровой экономики, обладающих средней и низкой квалификацией, достигает колоссальных размеров, практически не имеющих аналогов в традиционных организационно-технологических укладах.

Таким образом, правомерно говорить о новых формах организации и эксплуатации наемного труда в условиях цифровой экономики, а не о переходе к эре «равных возможностей» даже в рамках цифровой сферы. При этом, наряду с цифровым организационно-технологическим укладом сохраняются традиционные организационнотехнологические уклады, которые лишь частично подвергаются цифровизации. «Любая экономическая система не бывает полностью однородна, обычно ее основу составляют наиболее прогрессивные виды и типы экономических отношений, которые окружены эксполярными образованиями» [6, с. 53]. В рамках названных укладов действуют свои, иногда достаточно специфические, способы организации трудовых отношений и распределения добавленной стоимости между собственниками факторов производства.

Остановимся на еще одном высказывании Г. Г. Головенчик: «Многие эксперты считают, что страхи перед тотальной автоматизацией сильно преувеличены. Они предполагают, что роботы возьмут на себя низкооплачиваемый труд и рутинные операции. Это сделает производственные процессы более эффективными, исключит вероятность человеческой ошибки и поможет людям выделять время на более творческую работу» $[4$, с. 32]. В данном случае, по нашему мнению, у названного автора также присутствует ряд противоречий. Прежде всего, в условиях рыночной экономики собственники стремятся замещать машинами живой труд тогда, когда физический труд 
обходится дороже. Поэтому роботы замещают, прежде всего, труд, который ценится на рынке дороже. Практика роботизации, внедрения ботов показывает, что наиболее быстро и последовательно замещается умственный труд - например, в банковской сфере именно потому, что там используют роботов без материальной (физической) оболочки. А уже после того, как этот сегмент (ботов без физической оболочки) оказывается заполненным, начинается активное внедрение роботов в другие сферы, причем если в этом нет острой технологической необходимости (т. е. если отставание в роботизации не повлияет на конкурентоспособность производимой продукции), то решающим будет экономическая целесообразность. При рассмотрении перспектив влияния цифровизации и роботизации на рынок труда нельзя подменять анализ реальных экономических процессов «мечтами» о том, что вот она - та новая технология, которая облагодетельствует человечество. Усиление творческой компоненты в труде многих работников - не только и не столько технологический, сколько политикоэкономический, социальный, духовный и нравственный процесс.

В указанном контексте, анализируя динамику трудовых отношений в Республике Беларусь в условиях развития цифровой экономики, следует отметить такую тенденцию, как замена ботами без физической оболочки средне- и низкоквалифицированных работников умственного труда, занятых в банковской сфере, а в ближайшей перспективе (исходя из существующих тенденций в странах ОЭСР) - и юристов, специализирующихся на гражданском процессе, бухгалтеров, маркетологов, финансовых аналитиков и т. д. Согласно исследованиям, в период с 2018 г. по 2022 г. наибольшему риску замещения машинами и алгоритмами подвержены занятые рутинной деятельностью среднеквалифицированные «белые воротнички» - «такие, как операторы ввода данных, бухгалтеры по расчету заработной платы и учету материалов, клерки, секретари, аудиторы, кассиры, т. е. выполняющие процессы, наиболее восприимчивые к достижениям в области новых технологий и легко поддающиеся автоматизации» [7, с. 57].

Поскольку применение ботов без материальной (физической) оболочки достаточно ограничено, то после того, как ресурс роботизации в финансовой, торговокоммерческой и юридической сферах будет значительно исчерпан, следует ожидать перемещения внимания разработчиков на реальный сектор экономики. Все это будет сказываться на изменении трудовых отношений и рынка труда. Сокращение численности сотрудников, занятых средне- и низкоквалифицированным умственным трудом в сфеpax народного хозяйства, подвергшихся ускоренной роботизации, неизбежно окажет влияние на рынок труда и трудовые отношения. «Влияние роботизации на занятость будет проявляться в кардинальных изменениях ее структуры <..> На макро- и микроуровнях трансформации структуры занятости будут сопровождаться социальной неустойчивостью и изменениями в распределении доходов» [8, с. 779], - отмечалось нами ранее по этому поводу. Представляется маловероятным, что результаты структурной безработицы, которая неизбежно возникнет в этом случае, будут легко устранимы. Далеко не все индивиды, занятые сегодня средне- и низкоквалифицированным (как правило, не творческим) умственным трудом в банковской сфере, юриспруденции, бухгалтерском учете, маркетинге, финансовом анализе и т. д., смогут найти себе другую работу. Эту ситуацию могут усугубить также сложившиеся тенденции в выборе работодателями приоритетных категорий персонала для обучения и повышения квалификации. Так, согласно исследованиям, «участие в обучении работников с низкой квалификацией на 40 \% ниже, чем у работников с высокой квалификацией, что значительно облегчает последним переход из сокращающихся секторов занятости в расширяющиеся» [9, с. 119]. В более отдаленной перспективе, возможно, при переходе к квантовым компьютерам, также должно значительно сократиться количество программистов.

Все эти работники привыкли к определенному уровню жизни, гарантированному доходу и не очень тяжелому умственному труду. Не многие из них будут готовы 
переквалифицироваться и заняться творческим трудом (поскольку склонность к творческой деятельности и соответствующие навыки не появляются по приказу, а напротив - требуют специфического склада ума, особого воспитания и длительной подготовки особым образом жизни). Не многие из них будут готовы заняться физическим или умственно-физическим трудом. Таким образом, в результате эволюции трудовых отношений в контексте развития цифровой экономики в Республике Беларусь возникнет дополнительная социально-экономическая напряженность как следствие значительной структурной безработицы. «Реальные процессы высвобождения персонала, обусловленные роботизацией, сопровождаются ростом структурной безработицы, негативные эффекты которой амортизируются силами государственной социальной поддержки. Это, в свою очередь, приводит к формированию рентных настроений в обществе» $[10$, с. 75$]$. Для того, чтобы это не привело к социальному взрыву, необходимо уже сегодня начинать работать над дорожной картой по минимизации этих социальнотрудовых и экономических проблем, разрабатывать механизмы формирования у структурных безработных новых механизмов мотивации к труду, искать, чем их можно занять с пользой для индивидов и общества. Как справедливо отмечают белорусские экономисты, «сегодня стало очевидным, что инновационное развитие белорусской экономики возможно лишь на основе более рационального использования трудовых ресурсов» [11, с. 2].

Вместе с тем, для той части трудоспособного населения и коммерческих организаций, которые найдут свое место в цифровой экономике, открываются значительные перспективы. Для работников - это возможность творческой работы, свободного графика труда (для тех, кто сможет соответствовать новым требованиям к человеческому капиталу и будет стремиться к высокому уровню персональной независимости от работодателя), более высокая оплата труда. Для коммерческих организаций - это информатизация производственных процессов (например, промышленный интернет вещей), делающая их более эффективными, снижающая вероятность человеческой ошибки, новые способы продвижения своих товаров и услуг и т. д. В качестве ключевых направлений преобразования промышленного производства под воздействием цифровизации Ю. В. Мелешко выделяет следующие: «индивидуализация продукции и переход к мелкосерийному производству при сохранении (или повышении) рентабельности», «флексибилизация производства», «оптимизированное принятие решений», «производительность и эффективность ресурсов», «создание добавленной стоимости с помощью новых услуг», «организация занятости с учетом демографических особенностей», «сбалансированность трудовой жизни», «высокий уровень добавленной стоимости» $[12$, с. $84-85]$. Такой вариант развития цифровой экономики в нашей стране будет тем успешнее, чем более амбициозные цели будут ставиться и реализовываться в рамках государственной структурной политики, которая «должна основываться на парадигмальной замене модели выживания отечественных предприятий реального сектора экономики на модель новой индустриализации, т. е. на формирование новой структуры народного хозяйства, основой которой должен стать сверхиндустриальный промышленный уклад» [13, с. 90].

В то же время цифровизация добавляет и еще одну новую сферу деятельности обеспечение безопасности информационных систем и ресурсов и защиты от кибератак. Российские исследователи О. Б. Дигилина и И. Б. Тесленко отмечают по этому поводу: «Рынок кибербезопасности достаточно сильно зависит от кибератак (серьезной проблемой стали sidechannel атаки) и новых уязвимостей в микропроцессорах различных компаний. В первом полугодии 2018 г. рынок высокотехнологичных хищений в России оценивался в 3,2 млрд руб. (547 млн руб. - хищения у юридических лиц с троянами для ПК; 192 млн руб. - хищения у физических лиц с Android-троянами). Большую угрозу стали представлять уже не атаки на банковский сектор, а атаки на правительственные учреждения. Интерес для киберпреступников также представляют 
энергетический сектор, системы промышленной автоматизации» [14, с. 170-171]. Очевидно, что по мере дальнейшего развития цифровой экономики количество работников, занятых обеспечением кибербезопасности в частном и государственном секторах, будут постоянно увеличиваться, а также будет повышаться уровень квалификации и компетенций тех, кто этим занимается профессионально.

Выводы. Проведенное исследование позволило установить, что преимущественно математическими методами нельзя охарактеризовать изменения, происходящие в динамике трудовых отношений в Республике Беларусь в условиях цифровизации и роботизации экономики. Проведенный анализ динамики трудовых отношений в Республике Беларусь показал, что этот процесс соответствует общемировым тенденциям, обеспечивая переход нашей страны к новому качеству экономического роста. При этом положительные эффекты для народного хозяйства будут тем выше, чем в большей степени удастся внедрять цифровые технологии и роботизированные системы в реальном секторе экономики, а также при наличии действенной государственной системы снижения уровня структурной безработицы, порождаемой дальнейшим развитием цифровой экономики.

\section{Список использованных источников}

1. Солодовников, С. Ю. Понятие хаоса и его место в развитии сложных систем / С. Ю. Солодовников // Экономическая наука сегодня : сб. науч. ст. / БНТУ. - Минск, 2018. - Вып. 7. - С. 5-18.

2. Солодовников, С. Ю. Теоретико-методологические основы исследования взаимосвязи теории трудовой мотивации и динамики трудовых отношений / С. Ю. Солодовников, Т. В. Сергиевич // Вестн. Полоц. гос. ун-та. Сер. D. Экон. и юрид. науки. 2016. - № 5. - C. 12-16.

3. Богатырева, В. В. Роль социального и человеческого капиталов в формировании и функционировании социально-экономической системы государства / В. В. Богатырева // Экономическая наука сегодня : сб. науч. ст. / БНТУ. - Минск, 2020. Вып. 11. - С. 5-11.

4. Головенчик, Г. Г. Трансформация рынка труда в цифровой экономике / Г. Г. Головенчик // Цифровая трансформация. - 2018. - № 4. - С. 27-43.

5. Богатырева, В. В. Новые и традиционные формы человеческого капитала в условиях развития цифровой экономики: постановка проблемы / В. В. Богатырева, Т. В. Сергиевич // Современное общество: проблемы, противоречия, решения : сборник научных трудов Межвузовского научного семинара; редкол.: Н. А. Вахтин [и др.]. 29 мая 2020 г., г. Санкт-Петербург / Санкт-Петербургский горный университет. - СПб, 2020. - C. 19-22.

6. Кузьмицкая, Т. В. Эволюция организации труда и управления промышленным производством / Т. В. Кузьмицкая // Экономическая наука сегодня : сб. науч. ст. / БНТУ. - Минск, 2019. - Вып. 9. - С. 50-62.

7. Кузьмицкая, Т. В. Динамика занятости в процессе осуществления четвертой промышленной революции / Т. В. Кузьмицкая // Экономическая наука сегодня : сб. науч. ст. / БНТУ. - Минск, 2019. - Вып. 10. - С. 55-60.

8. Сергиевич, Т. В. Некоторые политико-экономические аспекты исследования влияния роботизации на занятость в промышленности / Т. В. Сергиевич // Большая Евразия: Развитие, безопасность, сотрудничество. Ежегодник. - М.: ИНИОН РАН, 2020. - Вып. 3, ч. 2. - С. 778-780.

9. Кузьмицкая, Т. В. Направления государственной политики содействия занятости в постиндустриальной экономике / Т. В. Кузьмицкая // Экономическая наука сегодня : сб. науч. ст. / БНТУ. - Минск, 2020. - Вып. 11. - С. 117-124. 
10. Сергиевич, Т. В. Социально-экономическая обусловленность роботизации экономики / Т. В. Сергиевич // Вестник Института экономики НАН Беларуси : сб. науч. ст. / Национальная академия наук Беларуси, Институт экономики НАН Беларуси. - Минск, 2020. - Вып. 1. - С. 68-77.

11. Солодовников, С. Ю. Тенденции и перспективы развития занятости и создания социально-научного сообщества в условиях модернизации транзитивной экономики: на примере Республики Беларусь / С. Ю. Солодовников // Вестн. Полоц. гос. унта. Сер. D. Экон. и юрид. науки. - 2015. - № 6. - С. 2-9.

12. Мелешко, Ю. В. Индустрия 4.0 - новая промышленная политика Германии: теоретическая основа и практические результаты / Ю. В. Мелешко // Экономическая наука сегодня : сб. науч. ст. / БНТУ. - Минск, 2018. - Вып. 8. - С. 80-93.

13. Солодовников, С. Ю. Взаимосвязь структурной политики государства и модернизации реального сектора экономики / С. Ю. Солодовников // Экономическая наука сегодня : сб. науч. ст. / БНТУ. - Минск, 2018. - Вып. 7. - С. 84-94.

14. Дигилина, О. Б. Трансформация рынка труда в условиях цифровизации / О. Б. Дигилина, И. Б. Тесленко // Вестник РГГУ. Серия «Экономика. Управление. Право». - 2019. - № 4. - С. 166-181. DOI:10.28995/2073-6304- 2019-4-166-180.

Статья поступила в редакиию 25 марта 2021 года

\title{
EVOLUTION OF LABOR RELATIONS IN THE REPUBLIC OF BELARUS IN THE CONTEXT OF DIGITALIZATION AND ROBOTIZATION OF THE ECONOMY
}

\author{
V. V. Bogatyreva \\ Doctor of Economics, Professor, Rector \\ Vitebsk State University named after P. M. Masherov \\ Vitebsk, Republic of Belarus \\ M. Yu. Bobrik \\ $\mathrm{PhD}$ in Geography, Associate Professor, \\ Vice-rector for Academic Affairs \\ Vitebsk State University named after P. M. Masherov \\ Vitebsk, Republic of Belarus \\ T. V. Serhiyevich \\ $\mathrm{PhD}$ in Economics, Associate Professor, \\ Associate Professor of the Department "Economics and Law" \\ Belarusian National Technical University \\ Minsk, Republic of Belarus
}

The article is devoted to the study of the evolution of labor relations in the Republic of Belarus. It was revealed that the dynamics of labor relations in the Republic of Belarus corresponds to global trends, ensuring the transition of our country to a new quality of economic growth. It is concluded that the positive effects for the national economy will be the higher, the more it is possible to introduce digital technologies and robotic systems in the real sector of the economy, as well as in the presence of an effective state system for reducing the level of structural unemployment generated by the further development of the digital economy.

Keywords: labor relations, human capital, labor motivation, digital economy, robotization of the economy, structural unemployment, labor market. 


\section{References}

1. Solodovnicov, S. Yu. (2018) Ponyatie khaosa i ego mesto v razvitii slozhnykh sistem [Chaos definition and its role in complicated systems' developement]. Ekonomicheskaya nauka segodnya. (7), 5-18. (In Russian).

2. Solodovnikov, S. Yu., Serhiyevich, T. V. (2016) Teoretiko-metodologicheskie osnovy issledovaniya vzaimosvyazi teorii trudovoi motivatsii i dinamiki trudovykh otnoshenii [Theoretical and methodological basics of the research of the correlation of the labor motivation theory and the dynamic of labor relations]. Herald of Polotsk state university. Series D. Economics and law sciences. (5), 12-16. (In Russian).

3. Bogatyreva, V. V. (2020) Rol' sotsial'nogo i chelovecheskogo kapitalov v formirovanii i funktsionirovanii sotsial'no-ekonomicheskoi sistemy gosudarstva [The role of social and human capital in the formation and functioning of the socio-economic system of the state]. Ekonomicheskaya nauka segodnya. (11), 5-11. (In Russian).

4. Golovenchik, G. G. (2018) Transformatsiya rynka truda v tsifrovoi ekonomike [Transformation of the labor market in the digital economy]. Tsifrovaya transformatsiya. (4), 27-43. (In Russian).

5. Bogatyreva, V. V., Serhiyevich, T. V. (2020) Novye i traditsionnye formy chelovecheskogo kapitala $\mathrm{v}$ usloviyakh razvitiya tsifrovoi ekonomiki: postanovka problemy [New and traditional forms of human capital in the context of the development of the digital economy: formulation of the problem]. In: Vakhtin N. A. [and oth.] (eds.) Modern society: problems, contradictions, solutions: Collection of scientific papers of the Interuniversity scientific seminar, 29 May 2020, Saint Petersburg, Russia. Saint Petersburg, Saint Petersburg Mining University. 19-22. (In Russian).

6. Kuzmitskaya, T. V. (2019) Evolyutsiya organizatsii truda i upravleniya promyshlennym proizvodstvom [Evolution of work organization and management industrial manufacturing]. Ekonomicheskaya nauka segodnya. (9), 50-62. (In Russian).

7. Kuzmitskaya, T. V. (2019) Dinamika zanyatosti v protsesse osushchestvleniya chetvertoi promyshlennoi revolyutsii [Dynamics of employment in the process of implementing the fourth industrial revolution]. Ekonomicheskaya nauka segodnya. (10), 55-60. (In Russian).

8. Serhiyevich, T. V. (2020) Nekotorye politiko-ekonomicheskie aspekty issledovaniya vliyaniya robotizatsii na zanyatost' $\mathrm{v}$ promyshlennosti [Some political and economic aspects of the study of the impact of robotization on employment in industry] Greater Eurasia: Development, Security, Cooperation. Yearbook. M .: INION RAN, 2020. (3). 2. 778-780. (In Russian).

9. Kuzmitskaya, T. V. (2020) Napravleniya gosudarstvennoi politiki sodeistviya zanyatosti v postindustrial'noi ekonomike [Directions of state policy of promoting employment in a post-industrial economy]. Ekonomicheskaya nauka segodnya. (11), 117-124. (In Russian).

10. Serhiyevich, T. V. (2020) Sotsial'no-ekonomicheskaya obuslovlennost' robotizatsii ekonomiki [Socio-economic conditionality of robotization of the economy]. Bulletin of the Institute of Economics of the NAS of Belarus. (1), 68-77. (In Russian).

11. Solodovnikov, S. Yu. (2015) Tendentsii i perspektivy razvitiya zanyatosti i sozdaniya sotsial'no-nauchnogo soobshchestva $\mathrm{v}$ usloviyakh modernizatsii tranzitivnoi ekonomiki: na primere Respubliki Belarus' [The tendencies perspectives of the employment development and creation of the social and science association under the conditions of modernization of the transitive economy: on the example of Republic of Belarus]. Herald of Polotsk state university. Series D. Economics and law sciences. (6), 2-9. (In Russian).

12. Meleshko, Yu. V. (2018) Industriya 4.0 - novaya promyshlennaya politika Germanii: teoreticheskaya osnova i prakticheskie rezul'taty [Industry 4.0 - new industrial policy of Germany: theoretical basis and practical results]. Ekonomicheskaya nauka segodnya. (8), 80-93. (In Russian). 
13. Solodovnicov, S. Yu. (2018) Vzaimosvyaz' strukturnoi politiki gosudarstva i modernizatsii real'nogo sektora ekonomiki [Relationship of structural policy of the state and modernization of the real sector of economics]. Ekonomicheskaya nauka segodnya. (7), 8494. (In Russian).

14. Digilina, O. B., Teslenko, I. B. (2019) Transformatsiya rynka truda v usloviyakh tsifrovizatsii [Transformation of the labor market in the context of digitalization]. Vestnik RGGU. Seriya «Ekonomika. Upravlenie. Pravo». (4), 166-181. Available from: doi:10.28995/2073-6304- 2019-4-166-180. (In Russian). 